\title{
DEVELOPMENT OF 5D BIM-BASED MANAGEMENT SYSTEM FOR PRE-FABRICATED CONSTRUCTION IN CHINA
}

\author{
C. Chen ${ }^{1 *}$, L. C. M. Tang' ${ }^{2}$ and Y. Jin ${ }^{1}$ \\ ${ }^{I}$ Department of Architecture and Built Environment, University of Nottingham, Ningbo, China \\ ${ }^{2}$ Department of Real Estate and Construction, Faculty of Architecture, The University of Hong Kong, Hong Kong, China \\ * Corresponding author
}

\begin{abstract}
Nowadays, the dramatic growth of global population and the rapid development of urbanization are the main reasons of a continuously increasing demand for thousands of architecture, engineering and construction (AEC) projects particularly in China, which is the largest AEC market in the world. However, along with that come severe challenges of high energy consumptions, massive resource wastes and serious productivity decline to the traditional AEC industry in China. Therefore, a technological concept named pre-fabricated construction is being highly embraced in recent years to help solve these challenges and meanwhile realize "Lean Construction" which is mentioned in the sustainable development of urbanization. This concept is proposed for decades, but its implementation in practice is facing technical barriers including lack of efficient management patterns, inefficient collaborations of stakeholders, outdated means of information collection and processing. To overcome these barriers and narrow the gap between the concept and practice, an emerging digital technology called Building Information Modelling (BIM) is suggested to accelerate the digitalization of AEC industrial management pattern and the implementation of efficient pre-fabricated construction. This paper aims to introduce an innovative framework for a digital management system that integrates the concept of five-dimensional (5D) BIM with the technique of radio frequency identification devices (RFID). This BIM-based system is developed in order to realize efficient management from off-site pre-fabrication stage to on-site assembly phase for pre-fabricated construction projects in China. It is also expected that 5D BIM can provide modeling, schedule simulation, and cost estimation to maximize the value of information flow for improving the productivity of pre-fabricated construction process.
\end{abstract}

\section{Introduction}

In recent years, with the rapid expansion of urbanization, China's architecture, engineering, and construction (AEC) industry are facing numerous challenges such as massive resource waste, high energy consumption and environmental severe pollution (Gerbert et al., 2016). As the largest AEC market in the world, China is struggling to implement the industrial transformation from traditional extensive pattern to sustainable development, which refers to the implementations of new technological concepts due to their potential contributions to the increase of productivity and the decrease of resource wastes and energy consumptions (Chen et al., 2017).

Pre-fabricated construction is one of the most innovative technological concepts for modern AEC industry (Hong et al., 2018). By separating the traditional construction process into off-site prefabrication and on-site assembly, it can play a significant role to help realize "Lean Construction", which is a sustainable concept for the future development of AEC industry and urbanization (Nahmens and Mullens, 2011; Pereira and Cachadinha, 2011). However, there is still a large gap between the concept of pre-fabricated construction and practice due to the inefficient management pattern and the old information techniques in China's AEC industry (Hong et al., 2018). With the trend of digitalization all over the world, the traditional management pattern, which mainly depends on Computer-Aided Design (CAD) and two-dimensional (2D) drawings, cannot meet the demands of sustainable development in modern AEC projects anymore (Crotty, 2012).

Therefore, an emerging technology named Building Information Modelling (BIM) is proposed to solve this challenge for global and China's AEC industry. BIM is expected to serve as a powerful tool in realizing threedimensional (3D) representations of physical and functional characteristics of buildings in projects (Bheda et al., 2017). Compared with CAD drawings as the primary implementation way in the traditional management system, BIM can bring benefits depending on its advanced software tools during the project lifecycle. Under the help of BIM software tools, 3D visualization, design optimization, construction schedule simulation, and cost estimation can be realized through a digital construction model that contains valuable information from multi-disciplines such as architecture, civil engineering, procurement, construction supervision. (Eastman et al., 2011; Zhao et al., 2008). This is what a concept of "multidimensional BIM" indicates (Ding et al., 2014). It is defined that 3D modeling integrated with schedule simulation is fourdimensional (4D) BIM; 4D BIM integrated with quantity takeoff, and dynamic cost estimation is five-dimensional (5D) BIM (Pučko et al., 2014).

This paper aims to develop an innovative framework of a $5 \mathrm{D}$ BIM-based management system for pre-fabricated construction. This system is expected to implement the functions including 3D modeling, schedule simulation, cost 
estimation, component tracking and supervision on site and off site. This system is preliminarily designed based on the empirical investigation of requirements from China's AEC industry and the integration of 5D BIM with other advanced digital technologies, such as the radio frequency identification devices (RFID) mentioned in this paper. The system can be further extended and applied in different regions and countries based on local BIM standards and relevant policies. A case study in China is also elaborated in this paper to validate the feasibility and reliability of the developed management system for pre-fabricated construction in practice. It is expected that this study can not only propose an efficient way to promote digitalization, integration, and standardization of prefabricated construction in China, but also make a contribution to help narrow the knowledge gap between advanced theories and practice mainly in construction phase, and ultimately help improve the productivity and the sustainability of the whole industry.

The objectives of this paper include:

I. Review the current development situations of prefabricated construction and 5D BIM technology in China;

II. Collect and analyze empirical data from China's AEC practitioners to determine required functions for digital pre-fabricated construction soon;

III. Develop a system framework for implementing 5D BIMbased digital management with RFID technology for implementing digital pre-fabricated construction on site and off site in China;

IV. Validate the feasibility and the reliability of the BIMbased management system framework through a case study in China;

\section{Literature Review}

\subsection{Pre-Fabricated Construction in China}

According to the 13th Five-Year policy, the Ministry of Housing and Urban-Rural Development (MOHURD) emphasized the significance of digitalization in the AEC industry, particularly the pre-fabricated construction (MOHURD, 2015). As the traditional production pattern of China's AEC industry is facing numerous issues like high resource and energy consumption, low productivity, inferior quality and terrible environmental pollution, the concept of pre-fabricated construction has become a national strategy of China and an imperative trend of the AEC industrial development in the future ( $\mathrm{Li}, 2017)$. It also can be regarded as an outcome from the deep integration of construction industrialization and construction informationization, which have been mentioned in the National Plan on New Urbanization 2014-2020 (GOSC (General Office of the State Council), 2014) and Plan on Green Building (MOHURD, 2013) as the critical issues of implementing efficient urbanization in China. In fact, this concept has been proposed since the 1950s (Li et al., 2014); however, the great importance was not given to it until recent years, with the increase of production costs and the demand of sustainable development, the concept of
"Lean Construction" is embraced by global AEC industries (Pereira and Cachadinha, 2011). Pre-fabricated construction is regarded as one of the most efficient ways to realize "Lean Construction" by manufacturing building components, just like traditional product manufacturing in factories (Bernstein et al., 2011). It is hoped that the application of pre-fabricated construction can reduce wastes and resource consumptions, meanwhile improve the overall productivity in the construction phase.

However, there are still some challenges that need to be overcome before the pre-fabricated construction can bring real values for new AEC projects in China. These challenges are listed as following (Bildsten, 2011; Li et al. 2017, 2018):

1. Inefficiency in logistics and allocation of component items (fabricated by construction materials);

2. Inefficient collaboration and communication between stakeholders (including the project manager, owner, contractor, worker);

3. Lack of interoperability among heterogeneous information systems including off-site production, logistics transportation, on-site management;

4. Lack of real-time visualization for information management; 5. Lack of efficient techniques in activity supervision, schedule simulation, cost estimation, and risk analysis;

6. Lack of normative management system for the prefabricated construction process.

The challenges mentioned above are mainly caused by the technical gap between the pre-fabrication theory and the real construction process. Therefore, new developed digital technologies are expected to provide corresponding functions for solving each challenge. These functions as shown below are required by project stakeholders for higher productivity and lower risks:

1. Accurate tracking and positioning of component items;

2. Efficient collaboration and communication between stakeholders;

3. Efficient integration of heterogeneous information;

4. $3 \mathrm{D}$ visualization of the construction process and monitoring of component items;

5. Reliable activity supervision, schedule simulation, cost estimation, and risk analysis;

6. A normative management system based on AEC industrial standards.

\section{2 $5 D$ BIM}

The concept of 5D BIM was initially developed in 2008, the Association for the Advancement of Cost Engineering International (AACE), the American Society of Professional Estimators (ASPE), the General Services Administration (GSA) and the National Institute of Building Sciences (NIBS) formed an agreement to promote the collaboration and coordination of cost estimation and management throughout the project lifecycle (Smith, 2016). 5D BIM is defined as a fivedimensional representation of the physical and functional characteristics based on digital modeling of traditional AEC projects. The primary purpose of using $5 \mathrm{D}$ BIM is to 
implement an accurate and reliable cost estimation based on a 3D digital model and eliminates errors caused by manual measurements or estimations (Ustinovičius et al., 2015). 5D $\mathrm{BIM}$ is also regarded as a future trend for the integration of multi-disciplinary knowledge and decision making for building design and construction phase based on 3D modeling, schedule simulation (4D) and cost estimation (5D) (Redmond et al., 2012). It enables project stakeholders to visualize the progress of design and construction with related costs over time (Kehily and Underwood, 2017; Park and Cai, 2017). 5D $\mathrm{BIM}$ is not only valuable to the project design phase but also applicable to project management in the construction phase.

In global scope, some relevant researches indicate that 5D BIM can provide existing Quantity Surveying (QS) data for further cost estimation and scenario evaluation in project management (Smith, 2016; Olatunji et al., 2010; Frei et al., 2013). In 2014 , RICS published another 'International BIM Implementation Guide' for project cost management, which is concerned about project managers and contractors (Smith, 2016). This guide implicitly indicated that 5D BIM would become an inevitable trend of realizing digital cost management particularly for the project construction phase. Furthermore, it is also proposed to realize efficient Life Cycle Costing (LCC), which can be integrated with QS cost assessments or bill of quantities based on 5D BIM (Kehily and Underwood, 2017). This tight link between 5D BIM and QS can deliver better cost management with certainties in the design and construction phase (Olatunji et al., 2010; Frei et al., 2013). Project managers or owners can use 5D BIM to make a dynamic cost plan in real time and acquire feedback information on the variation of cost management. With the extension of in-depth studies on 5D $\mathrm{BIM}$, it is believed that an emerging framework will be implemented in China's AEC industry (Wong et al., 2011, Zhou et al., 2012).

In the last few years, the rapid development of BIM has provided opportunities for the cost management of AEC projects in China. 5D BIM also has attracted the concerns from contractors and owners due to its intuitive analysis of cash flow and cost control in the construction phase (Jiang, 2017; Jupp, 2017). The 5D concept enables project stakeholders to visualize the progress of design and construction with related costs over time (Kehily and Underwood, 2017; Park and Cai, 2017). Furthermore, to minimize the uncertainties that may result in delays to the completion of the construction phase, activity supervision and risk analysis are also mentioned in 5D BIM. These functions can help stakeholders to optimize the initial schedule planning of the construction process and enhance its planning efficiency (Nguyen et al., 2013). Therefore, considering the benefits mentioned above, 5D BIM has been embraced by some experts and institutions and would play an essential role in the future BIM-based project management (Mitchell, 2012; Jiang, 2017).

\subsection{RFID}

RFID is a wireless sensor technology that can capture and transmit information from or to a tag through electromagnetic signal and radio frequencies. In recent years, it also has been considered as a critical technology to realize tracking and identification of pre-fabricated component items through supply chains for lean construction purpose (Ergen et al., 2011; Torrent and Caldas, 2009). It has been used in construction supply chains, logistics and indoor localizations of building components (such as columns, beams, and walls. ) in order to increase productivity due to the advantages including ready availability, ease operation, affordable cost, high accuracy and reliability (Pradhan et al., 2009). It is claimed that RFID can be adopted in lifecycle management of a pre-fabricated construction project, particularly in construction component tracking, which is a crucial process throughout the off-site prefabrication to the on-site construction (Motamedi and Hammad, 2009).

The application of RFID can profoundly improve the accuracy and reliability of the component tracking processes, which are divided into three phases including off-site, delivery and onsite (Majrouhi and Limbachiya, 2010). A conventional RFID system contains an antenna, a transceiver (RFID reader) and a transponder (Radio Frequency tag). The basic working principle is to use the transceiver to detect the radio frequency emitted by transponders that are assigned and mounted on the component items to distinguish them. The antenna sets up an electromagnetic area where the tag detects the activation signal and responds by transmitting the stored data from its memory chip through radio frequency waves (Li et al., 2018). Then the information of the tagged item can reveal on the host terminal (professional tracking software and computer) by receiving the signal from the reader (Majrouhi, 2012). RFID can be applied to monitor statuses of unit components from off-site prefabrication stages to on-site assembly stages while Global Position System (GPS) can be adopted to locate the unit components during logistics phase and predict the arrival time at the construction site (Torrent and Caldas, 2009). Such a method realizes not only automatic tracking of component items without labor input but also eliminates potential manual errors.

\subsection{Supply Chain Management of Pre-Fabricated Construction}

As the pre-fabricated construction refers to a supply chain which covers off-site prefabrication, logistical delivery, on-site receiving and stacking, efficient management is urgently required for this supply chain in order to reduce unfavourable impacts caused by uncertainties during the supply chain and meanwhile improve off-site productivity of pre-fabricated construction (Zhai et al., 2018).

RFID has been proposed as an appropriate method to increase management efficiencies of pre-fabricated construction supply chains due to automated tracking of pre-fabricated components. However, a detailed assessment of the benefits that RFID can bring for supply chains is still limited due to a lack of simulation results provided by digital modelling (Ergen et al., 2011). Thus advanced simulation modelling is needed to help owners and managers make decisions throughout the construction supply chain. Furthermore, production hedging issue also should be considered in the pre-fabricated construction projects as it can influence the efficiencies of supply chains owing to prefab production uncertainties (Zhai 
et al. 2017). Coordination systems based on digital modellings can be a practical approach to address this issue.

Therefore, the use of BIM suggests an optimal solution for realizing digital simulations and modellings of pre-fabricated construction supply chains (Goyal and Gao, 2018). Its integration with RFID not only can solve the lack of coordination in supply chains, but also can provide multidimensional functions (including 3D visualizations, 4D simulations, and 5D estimations, etc.) to reduce uncertainties and improve productivity during the pre-fabricated construction process, and eventually achieve the lean construction purpose.

\section{Methodology}

The methodology of this research is divided into four main steps, including empirical data collection, tool selection, system development and case study. The schematic workflow of the methodology is shown in Figure 1. Input and output of each step are also clarified.

As this research aims to accelerate BIM applications on prefabricated construction, it is necessary to understand the opinions and attitudes of practitioners from China's AEC industry on BIM (Jin et al., 2017). Therefore, an online survey was launched to collect empirical data for determining the functions that BIM can provide to meet the requirements of project stakeholders in the construction phase. The statistical results of the survey are used as empirical data to determine the required functions that BIM can provide for pre-fabricated construction in China. The second step is to select appropriate 5D BIM software, which is applicable for this research to implement the required functions including digital visualization of the pre-fabricated construction process and other 5D BIM functions including activity supervision, schedule simulation, cost estimation, and risk analysis.

After selecting the appropriate 5D BIM tool, the third step is to develop a digital management system based on traditional management pattern by integrating 5D BIM with other supporting technologies for pre-fabricated construction such as RFID. This system currently is a framework-based prototype, which indicates the compositions of the system.

When the BIM-based management system is developed, the next step is to validate its feasibility in practice. A typical case study of pre-fabricated construction in China is adopted to implement this step. Eventually, the findings from the case study will be used as evidence to evaluate the feasibility of the developed system. If the answer is definite, this system will be further improved for practical applications in China's prefabricated construction projects.
Figure 1 Schematic workflow of methodology

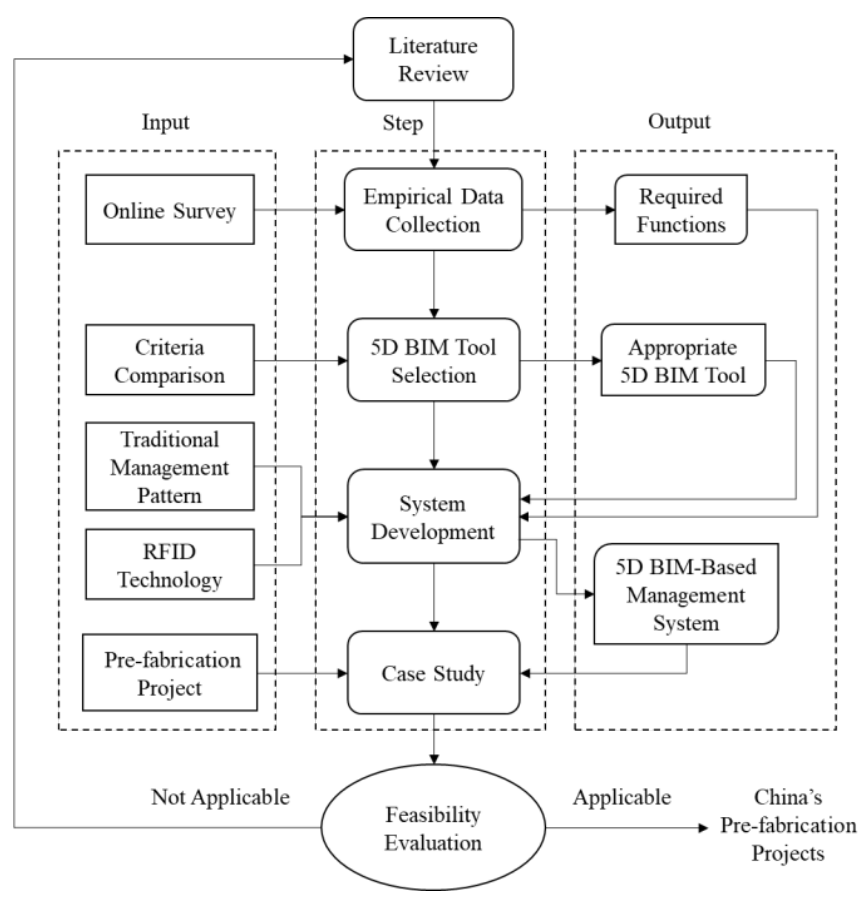

\section{Result Analysis}

The online survey for empirical data collection was conducted in January 2018. There were over 100 practitioners who are working in China's AEC industry participating in this survey. Each respondent only could submit one completed questionnaire as a valid response. After filtering the collected questionnaires (around 140 responses), there were 105 valid responses. Some key findings from the survey results are plotted in figures as shown below.

Figure 2.1 shows the distribution of the respondents' working years in the AEC industry. It is found that all the respondents have been working in the industry for more than one year and over half of them have working experience of 3 years at least. The respondents who have working experience of 10 years at least are mainly from construction organizations.

Figure 2.1 Distribution of respondents' working years in the AEC industry

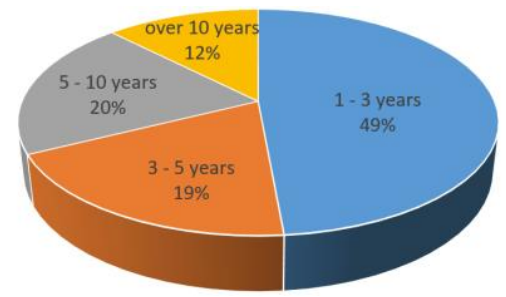

Figure 2.2 indicates the distribution of the respondents' professions in the industry. The most substantial proportion of the distribution is occupied by the project manager, and the least proportion is shared by the accountant, executive director, 
and quality inspector.

Figure 2.2 Distribution of respondents' professions

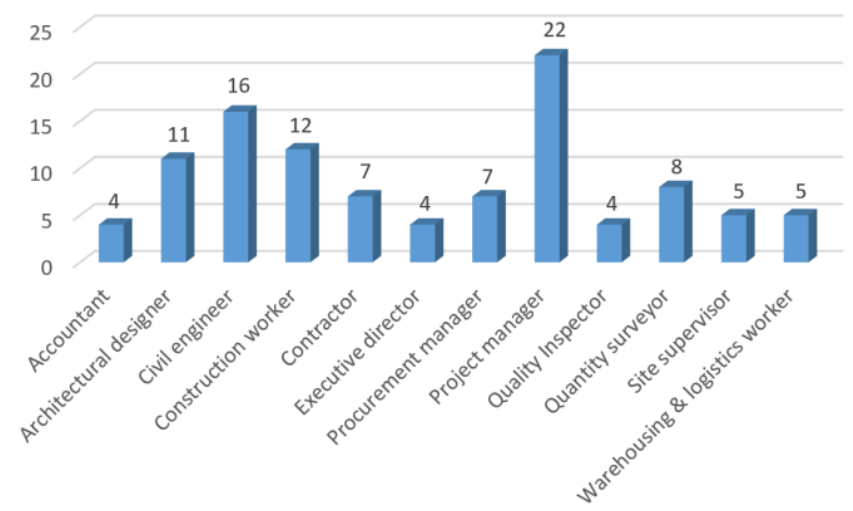

Figure 2.3 indicates the BIM proficiency of respondents. Here the BIM proficiency refers to the experience of using BIM software tools and participating in relevant BIM-based projects. It is found that over half of the respondents only have a primary BIM proficiency or even no experience. Only 18 respondents have a BIM proficiency of high level or above. All of the 18 respondents have working experience in the AEC industry for over five years.

Figure 2.3 BIM proficiency of respondents

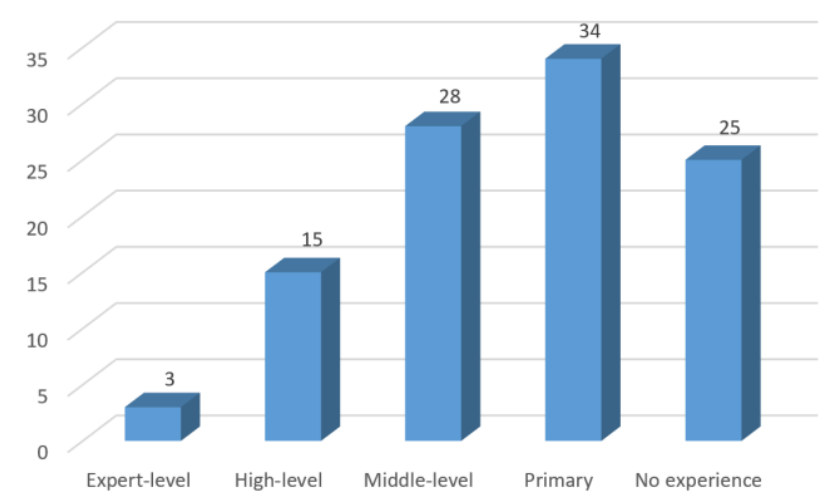

Figure 2.4 shows the ranking of significant functions that BIM can bring for the current construction process. According to the respondents' perspectives, over $60 \%$ of them thought $3 \mathrm{D}$ visualization, schedule simulation, collaboration enhancement, activity supervision, and cost estimation are the mainly required functions for digitalization of construction phase by using BIM. Besides, over $50 \%$ of them also thought real-time management, risk analysis, and safety management could be implemented through BIM application. It also should be mentioned that for respondents who have a BIM proficiency of expert level and high level (18 in total), schedule simulation (18 selected), collaboration (16 selected) and cost estimation (17 selected) are the top three required functions they selected for BIM application in the construction phase.
Figure 2.4 Required functions of BIM application in the construction phase

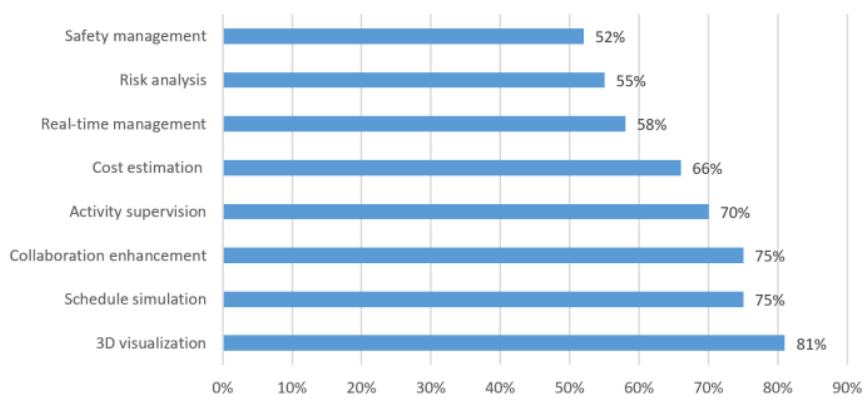

From the questionnaire results, there are three findings summarized as following. First, the BIM application is still at an early stage in China's AEC industry, which can be discovered from the results of BIM proficiency and BIM function ranking. The results indicate that the BIM application in China still focuses on Level 1 and the early stage of Level 2 (Dassault System, 2014; Kemp and Saxon, 2016). Second, it implicitly proves that BIM is experiencing rapid development in China's AEC industry through a result compared with an empirical investigation of China's BIM implementation in 2016. This is roughly known from a rapid proportion increase of practitioners with BIM proficiency in China's AEC industry (Jin et al., 2017). Third, BIM has become the key solution for various challenges of implementing sustainable construction phase, particularly for pre-fabrication. The required functions can be realized by integrating 5D BIM with other advanced digital technologies. These findings not only prove the substantial potential value of BIM in modern construction projects in China but also provide empirical data to support BIM application in pre-fabricated construction. This inspires the development of the BIM-based management system in this study.

After the required functions were determined according to the survey results, the next step is to select an appropriate 5D BIM software tool, which can potentially provide these functions directly or through secondary development. Table 1 shows a comparison among different 4D and 5D BIM software tools that are widely used for global or local AEC projects. These tools also have been tested according to potential service functions listed in Table 1. According to the findings from the Table 1 (Autodesk, 1997; Glodon, 2009; iTWO, 2018; Synchro, 2001), it is clearly understood that why the Vico Office software, which is developed by Trimble for 5D BIM purpose (Trimble, 2012), was finally selected as the software tool for the idea of potential secondary development in this research. 
Table 1 Comparison of 4D \& 5D BIM software

\begin{tabular}{|l|l|l|l|l|l|}
\hline Function & $\begin{array}{l}\text { Software } \\
\text { Microsoft } \\
\text { Project }\end{array}$ & Synchro & $\begin{array}{l}\text { Glodon } \\
\text { cubiCost }\end{array}$ & $\begin{array}{l}\text { iTWO } \\
\text { 5D } \\
\text { BIM }\end{array}$ & $\begin{array}{l}\text { Vico } \\
\text { Office }\end{array}$ \\
\hline 3D modeling & Yes & Yes & Yes & Yes & Yes \\
\hline Take-off quantity & Yes & No & Yes & Yes & Yes \\
\hline $\begin{array}{l}\text { Resource } \\
\text { allocation }\end{array}$ & No & Yes & Yes & Yes & Yes \\
\hline $\begin{array}{l}\text { Activity } \\
\text { supervision }\end{array}$ & Yes & Yes & Yes & Yes & Yes \\
\hline $\begin{array}{l}\text { Schedule } \\
\text { simulation }\end{array}$ & No & Yes & Yes & Yes & Yes \\
\hline Risk analysis & No & Yes & Weak & Weak & Yes \\
\hline $\begin{array}{l}\text { Quantity cost } \\
\text { estimation }\end{array}$ & Yes & No & Yes & Yes & Yes \\
\hline $\begin{array}{l}\text { Overall cost } \\
\text { estimation }\end{array}$ & $\begin{array}{l}\text { Rough } \\
\text { estimation }\end{array}$ & $\begin{array}{l}\text { Rough } \\
\text { estimation }\end{array}$ & Yes & Yes & Yes \\
\hline $\begin{array}{l}\text { Secondary } \\
\text { development } \\
\text { access }\end{array}$ & Yes & No & No & No & Yes \\
\hline
\end{tabular}

Through combining the empirical knowledge from traditional construction management pattern in China with the RFID technology and the required functions that 5D BIM tool can provide, it is possible to create a BIM-based system framework for the management of pre-fabricated construction. Figure 3.1 shows the essential data that can be categorized according to the required functions which will be implemented in the Vico Office. The geometric data and semantic relationships of building components are inherited from 3D models that are created in Autodesk Revit or other interoperable BIM modeling software to ensure the data consistency between 3D BIM and 5D BIM tools (Autodesk, 1997).

Figure 3.1 Data category based on the required functions

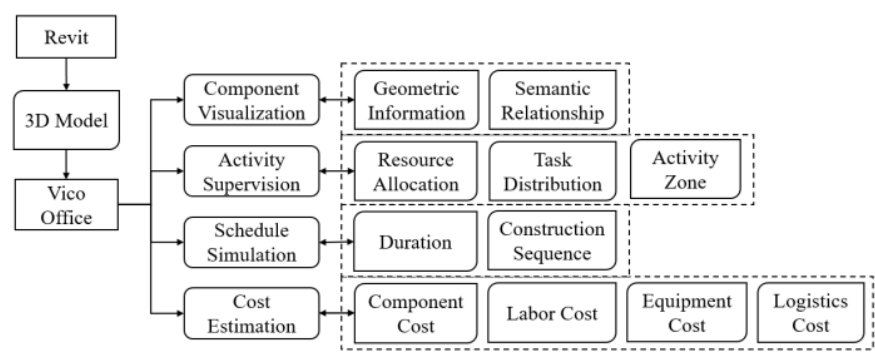

When model visualization, activity supervision, schedule simulation and cost estimation for construction are completed in Vico Office, the next step is to export the 5D BIM results in IFC (Industry Foundation Classes) data format and combine them with the component information provided by RFID system (Ma et al., 2011). The reason we select IFC for this study is due to its advantages of an open specification, international recognition and broad adoption over other data formats. These advantages of IFC have been approved in relevant researches for establishing collaborative digital construction environment (Fu et al., 2004; Ma et al., 2011). It can be seen from Figure 3.2 that the RFID system enables the services of real-time tracking and positioning for pre- fabricated component items from off-site production stage to on-site construction stage through logistic transportation. The real-time information of the pre-fabricated components can be stored in a cloud database for further operations such as exchange, transmission, updating ( $\mathrm{Xu}$ et al., 2018). The information then can be exported to the management platform, where the heterogeneous data from 5D BIM model and RFID database are integrated. This integration management platform allows the stakeholders to monitor, share, exchange and adjust real-time information of pre-fabricated components and construction planning based on an Internet of Things (IoT) (Zhong et al., 2017). A 5D BIM model is then generated on the management platform in order to realize 3D representations of pre-fabricated component characteristics and on-site assembly process. This model provides geometric information, semantic information and spatial referencing of its components for data integration and simulation in practical application (Shen et al., 2016). It can help stakeholders combine digital modelling with the real construction process for on-site supervision, collaboration, and production control.

Figure 3.2 Framework of the management system

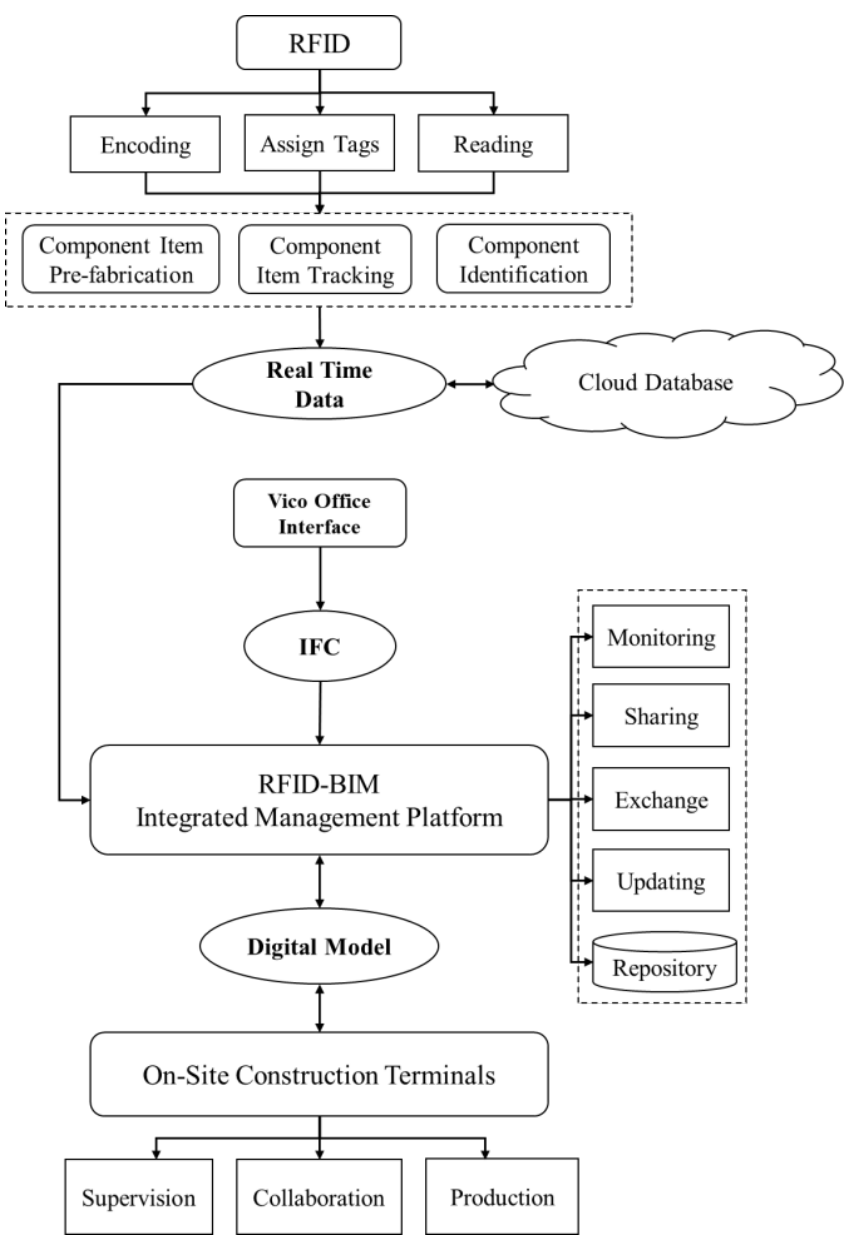

\section{Case Study}

To validate the feasibility and reliability of the developed system framework in the real pre-fabricated construction 
management, a new case study of China Resources Prefabricated Construction has been adopted in this research. It is a three-floor residential housing project located in Shanghai with a total design area of $1,100 \mathrm{~m}^{2}\left(360 \mathrm{~m}^{2}\right.$ for both ground floor and second floor, $380 \mathrm{~m}^{2}$ for the first floor) and a total design ground elevation of $19.03 \mathrm{~m}$. Its 3D BIM model was initially generated in Revit at the planning and design stage. Then the 3D model was imported to the Vico Office for activation. Based on the division of architectural floors, its prefabricated construction was also divided into three activity zones as shown in Figure 4.1.

Figure 4.1 Zone division for pre-fabricated construction

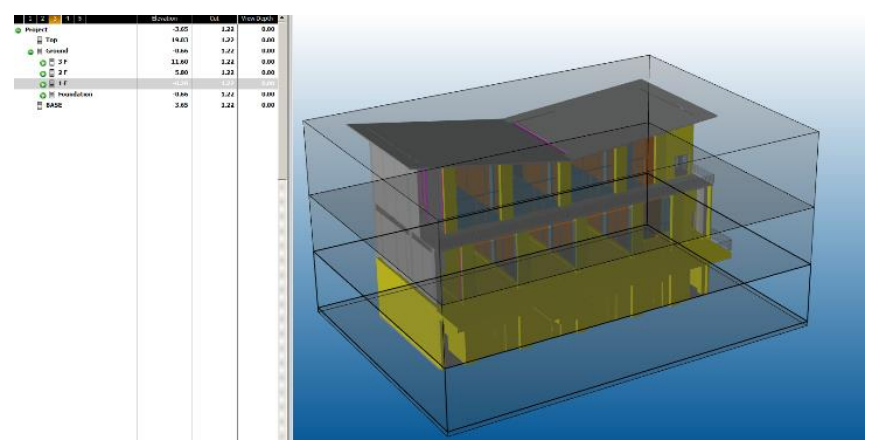

Also, the quantity take-off for the pre-fabricated components was also calculated and classified according to the division of activity zones (as shown in Figure 4.2). The calculation result can help construction managers to estimate the costs of prefabricated component materials, labors, equipment, and logistics accurately before the construction phase by using the mapping function in the Vico Office. They can also adjust the costs later according to the risk analysis for the real construction process. The cost estimation of this pre-fabricated construction project is shown in Figure 4.3.

Figure 4.2 Quantity take-off for the pre-fabricated components in 5D BIM

\begin{tabular}{|c|c|c|c|}
\hline Name & Type & Mappec & count \\
\hline Foundation Slab & - & Yes & \\
\hline F1 Column KZ & (10 & Yes & 17 \\
\hline F1 Column Reinforcement & है & Yes & 275 \\
\hline F1 Column Gz & (1) & Yes & 19 \\
\hline F1 Beam YKL & 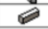 & Yes & 38 \\
\hline F1 BeamL & $\theta$ & Yes & 23 \\
\hline F2 Column Kz & [1] & Yes & 17 \\
\hline F2 Column Gz & (1) & Yes & 21 \\
\hline F2 Beam YKL & 8 & Yes & 17 \\
\hline F2 BeamL & 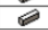 & Yes & 23 \\
\hline F3 Column Kz & [1] & Yes & 12 \\
\hline F3 Column GZ & (1) & Yes & 13 \\
\hline F3 Beam YKL. & $\ddot{B}$ & Yes & 19 \\
\hline F3 BeamL & $\theta$ & Yes & 26 \\
\hline F1-F2 Slab & - & Yes & 53 \\
\hline F2-F3 Slab & $=$ & Yes & 33 \\
\hline F1 St Wall & I & Yes & 33 \\
\hline F2 St Wall & $i$ & Yes & 24 \\
\hline F3 Str Wall & 1 & Yes & 20 \\
\hline Stair 1 & 8 & Yes & 24 \\
\hline Stair 2 & $\$$ & Yes & 23 \\
\hline Roof & A & Yes & 10 \\
\hline Archi Wall 1 & 1 & Yes & 32 \\
\hline Archi Wall 2 & $i$ & Yes & 83 \\
\hline Panel Wall & 1 & Yes & 274 \\
\hline Curtain Wall & \# & Yes & 139 \\
\hline Window & $\boxplus$ & Yes & 6 \\
\hline Fire Protection Door & 要 & Yes & 11 \\
\hline Glass Door & 而 & Yes & 12 \\
\hline Raling & 筒 & Yes & 6 \\
\hline Wood Panel & $B$ & Yes & 26 \\
\hline
\end{tabular}

Figure 4.3 Cost estimation of the pre-fabricated construction project in 5D BIM

\begin{tabular}{|c|c|c|c|c|}
\hline Description & aty & UOM & Unit Cost & Base Cost \\
\hline 4xiarest & 1.00 & & $397,514.50$ & A $397,514.50$ \\
\hline Wood Panel & 1.67 & $\mathrm{~m} 3$ & 100.46 & 168.21 \\
\hline Raling & 43.35 & $m$ & 137,67 & $5,967.61$ \\
\hline Glass Door & 58.39 & $\mathrm{~m} 2$ & 183.61 & $10,721.38$ \\
\hline Fire Protection Door & 31.65 & $\mathrm{~m} 2$ & 439.84 & $13,923.09$ \\
\hline Window & 17.01 & m2 & 212.08 & $3,607,45$ \\
\hline Curtain Wall & 185.00 & EA & 143.17 & $26,486.45$ \\
\hline Panel Wall & 73.48 & m3 & 350.19 & $25,732.52$ \\
\hline Archi Wall 2 & 62.77 & m3 & 386.92 & $24,287.46$ \\
\hline Archi Wall 1 & 46.82 & $\mathrm{~m} 3$ & 386.92 & $18,116.12$ \\
\hline Roof & 63.94 & m3 & 353.85 & $22,624.57$ \\
\hline Stair 2 & 13.90 & $\mathrm{~m} 3$ & 99.25 & $1,379.82$ \\
\hline Stair 1 & 14.29 & m3 & 99.25 & $1,418.58$ \\
\hline F3 Str Wall & 32.63 & $\mathrm{~m} 3$ & 350.37 & $11,433.19$ \\
\hline F2 Str Wall & 31.05 & m3 & 350.37 & $10,877,89$ \\
\hline F1 Str Wall & 31.50 & m3 & 350.37 & $11,034.97$ \\
\hline F2f3 Slab & 0.30 & $\mathrm{~m} 3$ & 361.25 & 106.59 \\
\hline F1F2 Slab & 0.00 & $\mathrm{~m} 3$ & 361.25 & 0.00 \\
\hline F3 Beam L & 11.15 & $\mathrm{~m} 3$ & 323.83 & $3,611,48$ \\
\hline F3 Beam YKL. & 13.87 & $\mathrm{~m} 3$ & 323.83 & $4,490.08$ \\
\hline F3 Column GZ & 3.01 & $\mathrm{~m} 3$ & 349.37 & $1,049.97$ \\
\hline F3 Column KZ & 21.64 & $\mathrm{~m} 3$ & 349.37 & $7,561.38$ \\
\hline F2 Beam L & 15.55 & m3 & 323.83 & $5,035.05$ \\
\hline F2 Beam YKL & 22.25 & m3 & 323.83 & $7,204.92$ \\
\hline F2 Column GZ & 6.90 & m3 & 332.23 & $2,291.60$ \\
\hline F2 Column KZ & 31.76 & $\mathrm{~m} 3$ & 349.37 & $11,096.39$ \\
\hline F1 Beam L & 17.35 & $\mathrm{~m} 3$ & 323.83 & $5,617.21$ \\
\hline F1 Beam YKL & 45.99 & $\mathrm{~m} 3$ & 323.83 & $14,892.35$ \\
\hline F1 Column GZ & 6.06 & $\mathrm{~m} 3$ & 332.23 & $2,014.51$ \\
\hline F1 Column & 0.06 & $\mathrm{~m} 3$ & $3,661,18$ & 219.83 \\
\hline F1 Column KZ & 32.97 & $\mathrm{~m} 3$ & 349.37 & $11,517.68$ \\
\hline Foundation Slab & 60.52 & $\mathrm{~m} 3$ & 422.96 & $25,596.86$ \\
\hline Piling & 60.52 & $\mathrm{~m} 3$ & 403.63 & $24,427.69$ \\
\hline Cast & 2.30 & $t$ & $3,100.00$ & $7,130.00$ \\
\hline Soil Treatment & 200.00 & $\mathrm{~m}$ & 66.81 & $13,362.00$ \\
\hline Backfill Earthwork & $1,090.00$ & m3 & 5.84 & $6,365.60$ \\
\hline Moving Outward & $1,450.00$ & $\mathrm{~m} 3$ & 31.25 & $45,312.50$ \\
\hline Excavation & $1,450.00$ & $\mathrm{~m} 3$ & 7.47 & $10,831.50$ \\
\hline
\end{tabular}

Furthermore, a schedule simulation for the pre-fabricated construction process was also conducted based on the planned construction sequence and duration as shown in Figure 4.4, which displays a timeline above the BIM model. Construction managers and decision makers can use the simulation to predict construction durations from the ground floor to roof installation and meanwhile check the real process with the simulation result for schedule risk analysis.

Figure 4.4 Schedule simulation of the pre-fabricated construction process from the ground floor to roof installation in 5D BIM

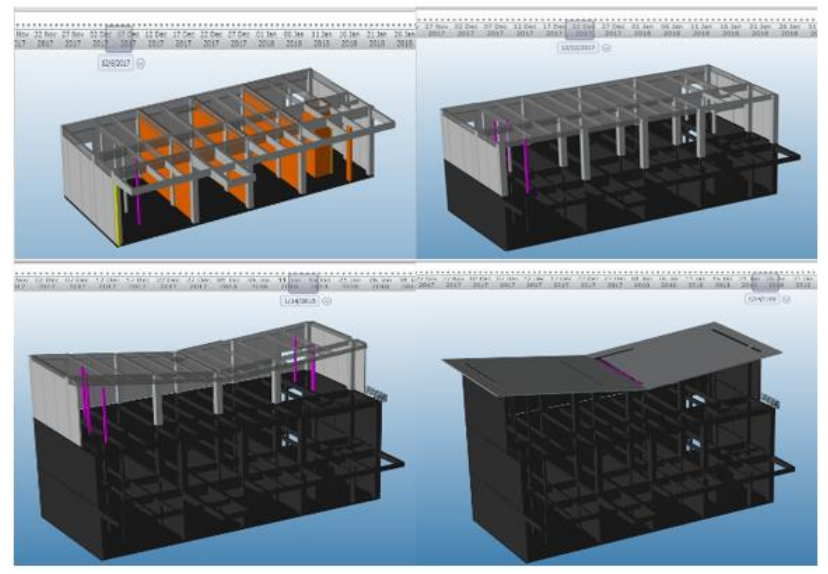


As the case study is still in the planning and design phase, the RFID technology will be later applied to the case for its supply chain management during the construction phase. Thus the research content introduced in this paper is still at an early stage under the current situation. As some appropriateness is usually assumed during the 5D BIM-based simulation and estimation process for feasibility assessment, it is still necessary to investigate the real performance of such a digital management system and its fitness with pre-fabricated construction supply chains in practice due to potential uncertainties caused by natural or human factors. Therefore, the integration of BIM-RFID data and tests from off-site prefabrication to on-site construction terminals will be validated in further relevant researches to prove the value of the 5D BIM-based management system in practical applications. Nevertheless, the current progress of the case study still shows the feasibility and reliability of the developed BIM-based management system for pre-fabricated construction in China.

\section{Conclusion}

There are still some challenges identified in this study. The first challenge is the heterogeneous data integration between IFC and RFID data. Although it is possible to combine these two data formats in theory, the accuracy and consistency of data after integration still require more validations from case studies in practice. The second challenge is the efficient connection between the system platform and IoT for realizing multidisciplinary collaboration under the current industrial background of various standards and various sub-workflows (Xu et al., 2018; Zhong et al., 2017). The third challenge is the cost of the whole management system. This cost involves not only the input of hardware including RFID systems, working stations, and control terminals but also the input of BIM software, web-based platform, and cloud database. Construction owners and decision makers may consider whether the benefits this system can bring for the prefabricated construction is worth such a high cost. It is expected that the cost can be reduced through mass production of customized hardware or corporation with BIM software vendors. Besides, the sustainable link between off-site prefabrication supply chains and on-site construction terminals is still weak in China as its pre-fabricated construction industry is currently at an early stage. Relevant management standards and patterns are needed for strengthening the link in order to meet the requirements of lean construction shortly.

Nevertheless, this study still provides a comprehensive review of current development situations of pre-fabricated construction and 5D BIM in China, offers detailed analysis of collected empirical data of required functions used for digitalization of pre-fabricated construction, and finally delivers an innovative framework of 5D BIM-based management system, which has been preliminarily validated for its feasibility and reliability in applications of prefabricated construction. In summary, this study not only provides an appropriate way to narrow the gap between 5D BIM theory and practice but also efficiently links the planning and design phase with construction phase and even later facility management phase by using digital information flow. It is hoped that these contributions can help realize the improvement of productivity and the reduction of wastes in the real pre-fabricated construction process.

\section{Acknowledgments}

The work presented in this research study was undertaken by the aegis of the BIM-GIS Application in Green Built Environment Project, funded by the Ningbo Science and Technology Bureau (2015B11011).

\section{References}

Autodesk Revit

https://www.autodesk.com/products/revit/overview (accessed 28/12/2018).

Bernstein HM et al. (2011) Prefabrication and Modularization - Increasing Productivity in the Construction Industry. McGraw-Hill Construction, Bedford, USA.

Bheda V et al. (2017) Building Information Modelling (BIM) as a Modern Approach for Managing Design and Management in Architecture, Engineering and Construction (AEC) Industry. International Journal of Research In Science and Engineering 2(3): 50-58.

Bildsten L (2011) Exploring the Opportunities and Barriers of Using Prefabricated House Components. 19th Conference of the International Group of Lean Construction (IGLC), Lima, Peru. Curran Associates, Inc., New York, USA, pp. 320-329.

Chen et al. (2017) BIM-Based Design Coordination for China's Architecture, Engineering and Construction Industry. 2nd International Conference on BIM (BIM 2017), Alicante, Spain. WIT Press, Southampton, UK, pp. 211-219.

Crotty R (2012) The impact of building information modeling transforming construction, 1st ed. Taylor and Francis, London, UK.

Dassault System (2014) End-to-end Collaboration Enabled by BIM Level 3.

Ding L et al. (2014) Building Information Modeling (BIM) application framework: The process of expanding from 3D to computable nD. Automation in Construction 46: 82-93.

Eastman C et al. (2011) A Guide to Building Information Modeling For Owners, Managers, Designers, Engineers, and Contractors. In: BIM Handbook. John Wiley \& Sons, Inc., New Jersey, USA.

Ergen E et al. (2011) Determining the Benefits of an RFIDBased System for Tracking Pre-Fabricated Components in a Supply Chain. American Society of Civil Engineers (ASCE) 291-298, 10.1061/41182(416)36.

Frei M et al. (2013) Critical success factors, opportunities and threats of the cost management profession: the case of Australasian quantity surveying firms. International Journal of Project Organisation and Management 5(1/2): 4-24, 10.1504/ijpom.2013.053151.

Fu C et al. (2004) IFC implementation in lifecycle costing. Journal of Harbin Institute of Technology 11(4): 437-441. 
Gerbert et al. (2016) Shaping the Future of Construction A Breakthrough in Mindset and Technology. The World Economic Forum, Geneva, Switzerland, Report REF-220416.

Glodon cubiCost (2009) https://cubicost.com (accessed 27/12/2018).

GOSC (2014) National Plan on New Urbanization 2014-2020. Beijing, China.

Goyal M and Gao Z (2018) Integration of Building Information Modeling (BIM) and Prefabrication for Lean Construction. American Society of Civil Engineers International Conference on Construction and Real Estate Management 2018, Charleston, South Carolina, USA, pp. 78-84.

Hong J et al. (2018) Barriers to promoting prefabricated construction in China: A cost-benefit analysis. Journal of Cleaner Production 172: 649-660.

iTWO 5D BIM (2018) https://www.itwo.com/cn (accessed 27/12/2018).

Jiang X (2017) Research on Application of BIM 5D Technology in Central Grand Project. Procedia Engineering 174: 600-610.

Jin $\mathrm{R}$ et al. (2017) An Empirical Study of BIMImplementation-Based Perceptions among Chinese Practitioners. Journal of Management in Engineering, ASCE 33(5), 10.1061/(ASCE)ME.1943-5479.0000538.

Jupp J (2017) 4D BIM for Environmental Planning and Management. Procedia Engineering 180: 190-201.

Kehily D and Underwood J (2017) Embedding Life Cycle Costing in 5D BIM. Journal of Information Technology in Construction 22: 145-167.

Kemp A and Saxon R (2016) BIM in the UK: Past, Present \& Future. UK BIM Alliance (UKBIMA).

Li CZ et al. (2014) Critical review of the research on the management of prefabricated construction. Habitat International 43: 240-249.

Li CZ et al. (2017) Integrating RFID and BIM technologies for mitigating risks and improving schedule performance of prefabricated house construction. Journal of Cleaner Production 165: 1048-1062.

Li CZ et al. (2018) An Internet of Things-enabled BIM platform for on-site assembly services in prefabricated construction. Automation in Construction 89: 146-161, 10.1016/j.autcon.2018.01.001.

Li L (2017) China's manufacturing locus in 2025: With a comparison of "Made-in-China 2025" and "Industry 4.0". Journal of Technological Forecasting and Social Change, 10.1016/j.techfore.2017.05.028.

Ma Z et al. (2011) Application and extension of the IFC standard in construction cost estimating for tendering in China. Automation in Construction 20(2): 196-204, 10.1016/j.autcon.2010.09.017.

Majrouhi SJ and Limbachiya MC (2010) Improving construction supply chain management with integrated application of RFID technology and portal system. 8th International Conference on Logistics Research (RIRL 2010), France.
Majrouhi SJ (2012) Influence of RFID technology on automated management of construction materials and components. Scientia Iranica 19(3): 381-392.

Mitchell D (2012) 5D - Creating Cost Certainty and Better Buildings. RICS Cobra Conference, Las Vegas, USA.

MOHURD (2013) Plan on Green Building. National Development and Reform Commission, Beijing, China.

MOHURD (2015) Development Outline of Informatization in the Construction Industry 2011-2015. http://www.gov.cn/gongbao/content/2011/content_2010588.h $\underline{\text { tm }}$ (accessed 04/06/2018).

Motamedi A and Hammad A (2009) Lifecycle management of facilities components using radio frequency identification and building information model. Journal of Information Technology in Construction 14: 238-262.

Nahmens I and Mullens MA (2011) Lean homebuilding: lessons learned from a precast concrete panelizer. Journal of Architectural Engineering, ASCE 17(4): 155-162.

Nguyen L et al. (2013) Simulating Construction Duration for Multistorey Buildings with Controlling Activities. Journal of Construction Engineering and Management, ASCE 139(8): 951-959.

Olatunji $\mathrm{O}$ et al. (2010) Building information modeling and quantity surveying practice. Emirates Journal for Engineering Research 15(1): 67-70.

Park J and Cai H (2017) WBS-based dynamic multidimensional BIM database for total construction as-built documentation. Automation in Construction 77: 15-23, 10.1016/j.autcon.2017.01.021.

Pereira D and Cachadinha N (2011) Lean Construction in Rehabilitation Works - Suitability Analysis and Contribution for the Definition of an Application Model. 19th Conference of the International Group of Lean Construction (IGLC), Lima, Peru. Curran Associates, Inc., New York, USA, pp. 157-167.

Pradhan A et al. (2009) Technological assessment of radio frequency identification technology for indoor localization. Journal of Computing in Civil Engineering 23(4): 230-238.

Pučko Z et al. (2014) Building information modeling based time and cost planning in construction projects. Organization, technology \& management in construction: An International Journal 6: 958-971.

Redmond A et al. (2012) Exploring how information exchanges can be enhanced through Cloud BIM. Automation in Construction 24: 175-183, 10.1016/j.autcon.2012.02.003.

Shen X et al. (2016) A Framework for Integrating Syntax, Semantics and Pragmatics for Computer-aided Professional Practice: With Application of Costing in Construction Industry. Computers in Industry 83: 28-45.

Smith P (2016) Project Cost Management with 5D BIM. Procedia - Social and Behavioral Sciences 226: 193-200, 10.1016/j.sbspro.2016.06.179.

Synchro Software (2001) https://www.synchroltd.com (accessed 20/02/2018).

Torrent DG and Caldas CH (2009) Methodology for automating the identification and localization of construction components on industrial projects. Journal of Computing in 
Civil Engineering 23(1): 3-13, 10.1061/(ASCE)08873801(2009)23:4(230).

Trimble Vico Office (2012) https://connect.trimble.com/feature/vico-office.html (accessed 25/11/2018).

Ustinovičius L et al. (2015) Innovative Research Projects in the Field of Building Lifecycle Management. Procedia Engineering 122: 166-171.

Wong KA et al. (2011) Building information modeling for tertiary construction education in Hong Kong. Journal of information technology in construction 16: 467-476.

Xu G et al. (2018) Cloud asset-enabled integrated IoT platform for lean prefabricated construction. Automation in Construction 93: 123-134, 10.1016/j.autcon.2018.05.012.

Zhai Y et al. (2017) Production lead-time hedging and coordination in prefabricated construction supply chain management. International Journal of Production Research 55(14): 3984-4002.

Zhai Y et al. (2018) Buffer space hedging and coordination in prefabricated construction supply chain management. International Journal of Production Economics 200(C): 192206, 10.1016/j.ijpe.2018.03.014.

Zhao Y et al. (2008) High value information in engineering organisations. International Journal of Information Management 28(4): 246-258.

Zhong RY et al. (2017) Prefabricated construction enabled by the Internet-of-Things. Automation in Construction 76: 59-70, 10.1016/j.autcon.2017.01.006.

Zhou L et al. (2012) Readiness of BIM: a case study of a quantity surveying organization. First $U K$ Academic Conference on BIM, Newcastle-upon-Tyne, UK. 